\title{
E-SKPI Fakultas Teknik Universitas Islam Riau
}

\author{
Des Suryani ${ }^{1}$, Ause Labellapansa ${ }^{2}$, Hendra Gunawan ${ }^{3}$ \\ ${ }^{1,2,3}$ Program Studi Teknik Informatika, Fakultas Teknik, Universitas Islam Riau \\ 12des.suryani@eng.uir.ac.id, ${ }^{2}$ ause.labella@eng.uir.ac.id, ${ }^{3}$ hendra@e @eng.uir.ac.id
}

\begin{abstract}
The application of Certificate of Companion Certificate (SKPI) to each new graduate or prospective undergraduate is a curriculum based on the Indonesian National Qualification Framework (KKNI). This is done so that every college graduate in addition to having a formal diploma also has SKPI related to a particular skill. Along with the application of new curriculum based on KKNI, Islamic University of Riau should continue to socialize to various faculties, especially the department as the spearhead of education implementation. One of the most important things of the KKNI is the enforcement of the policy of granting SKPI to every graduate. Now is the time, to improve the academic quality of the graduates also have a certificate of expertise outside the discipline of science. Based on this, to accelerate the process of granting SKPI to the graduates of the Faculty of Engineering, Islamic University of Riau needs an online system that can help the graduates, study programs and faculty leaders.
\end{abstract}

Keywords : Application, KKNI, SKPI

\begin{abstract}
Abstrak
Penerapan Surat Keterangan Pendamping Ijazah (SKPI) kepada setiap lulusan atau calon sarjana baru merupakan amanat kurikulum berbasis Kerangka Kualifikasi Nasional Indonesia (KKNI). Hal itu dilakukan agar setiap lulusan perguruan tinggi di samping memiliki ijazah formal juga memiliki SKPI yang terkait dengan keahlian tertentu. Seiring diterapkannya kurikulum baru berbasis KKNI, Universitas Islam Riau perlu terus mensosialisasikan ke berbagai fakultas, khususnya jurusan sebagai ujung tombak pelaksanaan pendidikan. Salah satu hal terpenting dari KKNI tersebut adalah pemberlakuan mengenai kebijakan pemberian SKPI kepada setiap lulusan. Sekarang ini sudah eranya, untuk meningkatkan mutu akademik para lulusan juga mempunyai sertifikat keahlian di luar disiplin ilmunya. Berdasarkan hal tersebut, untuk mempercepat proses pemberian SKPI tersebut kepada para lulusan fakultas Teknik Universitas Islam Riau perlu sebuah sistem secara online yang dapat membantu para lulusan dan program studi. Dengan sistem E-SKPI ini, semua mahasiswa Fakultas Teknik yang sudah menyelesaikan tugas akhirnya dapat menginputkan dan mengupload semua sertifikat yang terkait dengan bidang ilmunya. Program studi dapat melakukan verifikasi dan menghasilkan SKPI ini secara online untuk diberikan kepada para lulusan.
\end{abstract}

Kata Kunci : Aplikasi, KKNI, SKPI 


\section{PENDAHULUAN}

Berdasarkan Peraturan Menteri Pendidikan dan Kebudayaan Nomor 81 Tahun 2014 tentang ljazah, Sertifikat Kompetensi, dan Sertifikat Profesi Pendidikan Tinggi, dalam Pasal 5, disebutkan bahwa ijazah diberikan kepada lulusan perguruan tinggi disertai paling sedikit dengan Transkrip Akademik dan Surat Keterangan Pendamping ljazah (SKPI). Ketentuan tersebut mulai diberlakukan terhitung tanggal diundangkan yaitu 21 Agustus 2014.[1][2]

Surat Keterangan Pendamping ljazah (SKPI) atau Diploma Supplement adalah dokumen yang memuat informasi tentang pencapaian akademik atau kualifikasi dari lulusan pendidikan bergelar. Manfaat dari SKPI ini adalah sebagai dokumen tambahan yang menyatakan kemampuan kerja, penguasaan pengetahuan, dan sikap/moral seorang lulusan yang lebih mudah dimengerti oleh pihak pengguna di dalam maupun luar negeri; merupakan penjelasan yang obyektif dari prestasi dan kompetensi pemegangnya; dan meningkatkan kelayakan kerja (employability) terlepas dari kekakuan jenis dan jenjang program studi.

Seiring diterapkannya kurikulum baru berbasis KKNI, Universitas Islam Riau perlu terus mensosialisasikan ke berbagai fakultas, khususnya jurusan sebagai ujung tombak pelaksanaan pendidikan. Salah satu hal terpenting dari KKNI tersebut adalah pemberlakuan mengenai kebijakan pemberian SKPI kepada setiap lulusan. Penerapan SKPI kepada setiap lulusan atau calon sarjana baru merupakan amanat kurikulum berbasis Kerangka Kualifikasi Nasional Indonesia (KKNI). Sekarang ini sudah eranya, untuk meningkatkan mutu akademik para lulusan, mahasiswa tak hanya dibekali dengan ijazah formal tetapi juga harus punya sertifikat keahlian. Hal itu bertujuan agar para lulusan memiliki keahlian khusus lain di luar disiplin ilmunya.

Di samping itu, untuk menyongsong Masyarakat Ekonomi Asean (MEA), lulusan FT-UIR diharapkan tidak takut untuk bersaing. Setiap lulusan FT-UIR akan dibekali dengan SKPI yang berstandar ASEAN. Tujuannya untuk menjelaskan tentang keahlian lulusan FT-UIR yang lebih spesifik sesuai bidangnya. Pemberian SKPI ini menjadi sangat penting mengingat nanti lulusan FT-UIR harus mempunyai semacam pengakuan kompetensi.

Berdasarkan hal tersebut, untuk mempercepat proses pemberian SKPI tersebut kepada para lulusan fakultas Teknik Universitas Islam Riau perlu sebuah sistem yang dapat dijalankan secara online untuk membantu para lulusan, program studi maupun pimpinan fakultas.

\section{METODE PENELITIAN}

Penelitian ini dilakukan dalam beberapa tahapan. Gambar 1 merupakan metode penelitian yang digunakan untuk melakukan pembuatan aplikasi E-SKPI.[3][4] 


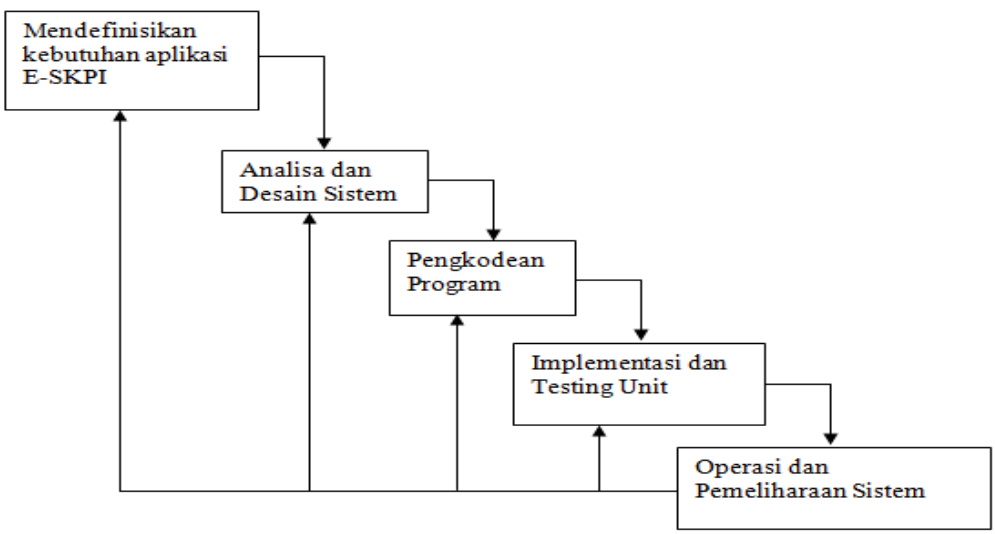

Gambar 1. Model Waterfall E-SKPI

\subsection{Pengembangan Sistem}

Perancangan sistem akan menjelaskan alur data atau aliran data pada sistem yang dibangun. Ada beberapa level dalam Data Flow Diagram (DFD) sistem informasi SKPI Fakultas Teknik yang dibangun yaitu context diagram dan DFD level 0.

\subsubsection{Context Diagram}

Context Diagram adalah suatu diagram yang digunakan untuk mendesain sistem yang memberikan gambaran umum mengenai semua sistem informasi yang diterima maupun dihasilkan dari suatu aktivitas. Diagram ini menggambarkan sebuah sistem pada bagian tengah tanpa informasi internal tentang sistem tersebut, dan dikelilingi oleh semua proses yang terkait. Gambar 2 menunjukkan Context Diagram pada sistem informasi SKPI Fakultas Teknik Universitas Islam Riau.

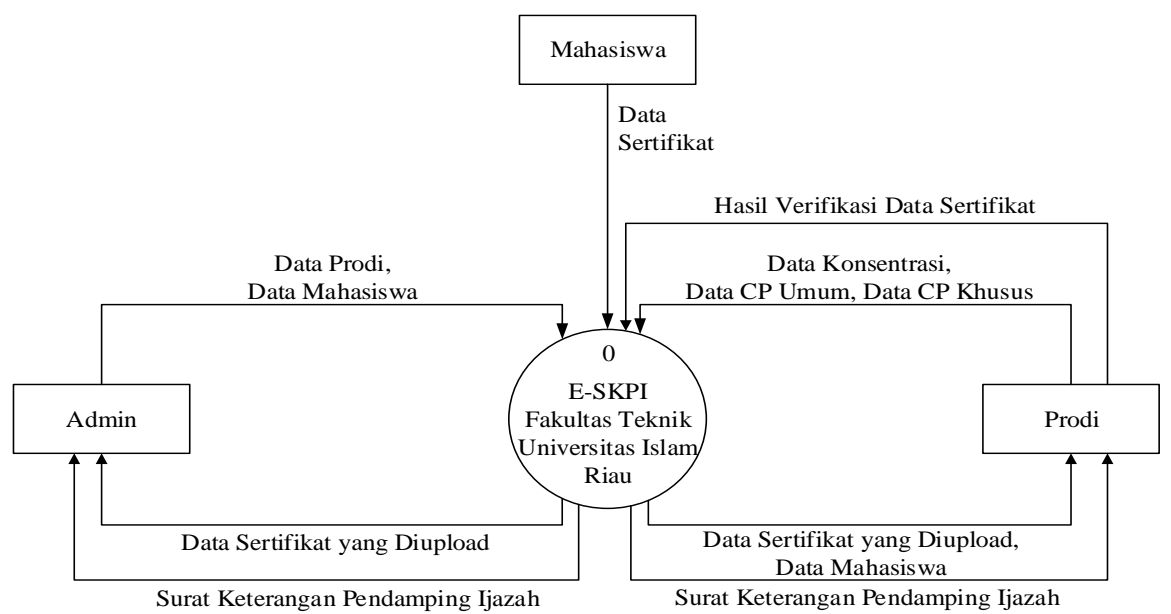

\section{Gambar 2. Context Diagram E-SKPI Fakultas Teknik Universitas Islam Riau}

\subsubsection{DFD Level 0}

Data Flow Diagram (DFD) level 0 berfungsi untuk menggambarkan suatu sistem yang telah ada atau sistem baru yang akan dikembangkan secara logika tanpa memperhatikan lingkungan fisik dimana data tersebut mengalir. Hal ini dapat digambarkan pada gambar 3 . 


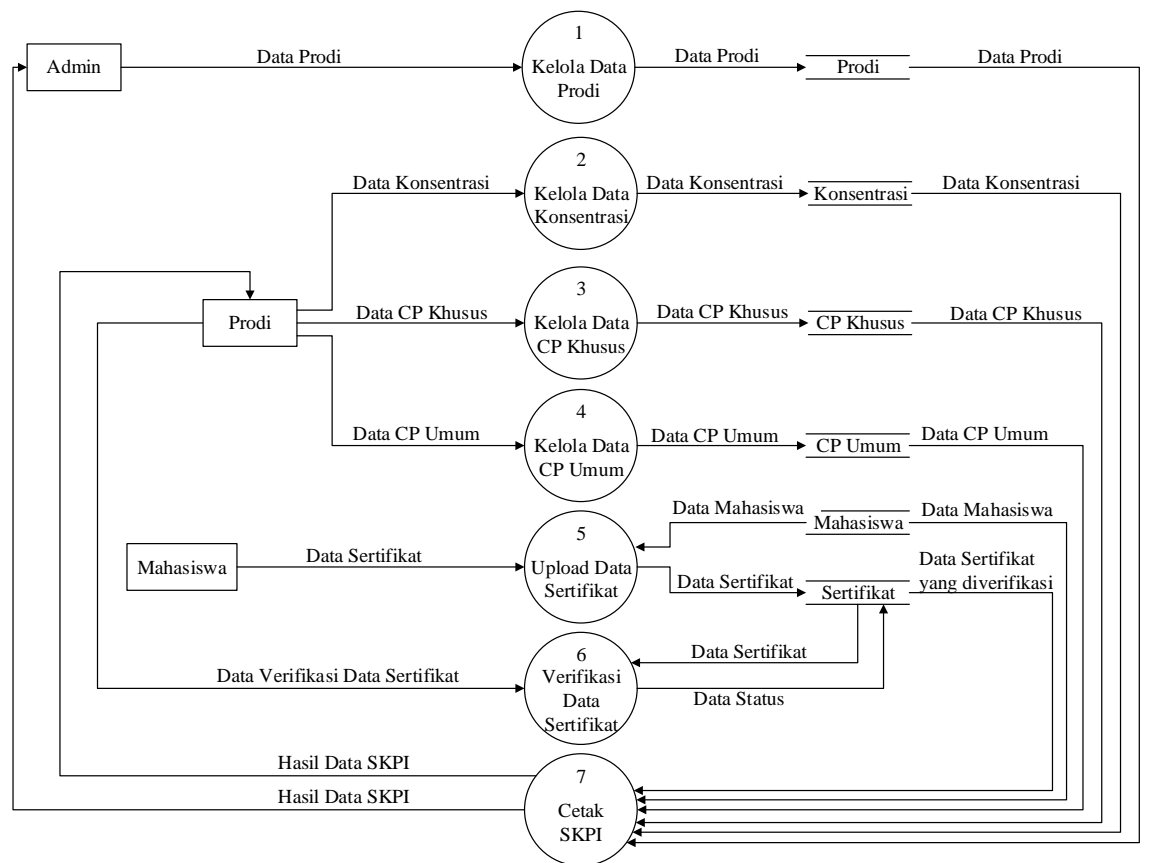

Gambar 3. DFD Level 0 Sistem E-SKPI Fakultas Teknik Universitas Islam Riau

\subsection{Perancangan Sistem}

Setelah dilakukan analisa dan altenatif pengembangan terhadap sistem yang akan akan dibuat, berikutnya dilanjutkan ke tahap perancangan sistem. Perancangan sistem yang dilakukan terdiri dari : [5][6][7]

1. Desain Output

Ada beberapa desain output terhadap sistem yang akan dijalankan oleh pengguna admin, prodi maupun mahasiswa diantaranya disain output login, mahasiswa, konsentrasi prodi, capaian pembelajaran umum, capaian pembelajaran khusus dan surat keterangan pendamping ijazah.

2. Desain Input

Ada beberapa desain input yang dirancang dalam pembangunan sistem E-SKPI Fakultas Teknik Universitas Islam Riau, diantaranya disain input data prodi, data konsentrasi prodi, capaian pembelajaran umum, capaian pembelajaran khusus dan input data sertifikat mahasiswa.

3. Desain : Database

Database merupakan komponen yang berperan sebagai tempat penyimpanan data yang telah diinputkan oleh pengguna sistem E-SKPI Fakultas Teknik Universitas Islam Riau. Desain Database yang dipakai dalam E-SKPI Fakultas Teknik Universitas Islam Riau dapat digambarkan Entity Relationship Diagram (ERD) adalah kumpulan file yang saling berkaitan. Pada model data relational, hubungan dengan file direlasikan dengan kunci relasi (relation key) yang merupakan kunci utama dari masing-masing file yang dapat dilihat pada gambar 4. 
IT Journal Research and Development

Vol.3, No.1, Agustus 2018

DOI : 10.25299/itjrd.2018.vol3(1).2091

e-ISSN: 2528-4053

4. Desain Logika Program

Desain logika program adalah skema atau bagan yang menunjukan aliran data didalam suatu program dan menggambarkan urutan logika dari suatu prosedur pemecahan masalah. Didalam sistem yang dibangun, terdapat beberapa desain logika program yang dirancang, diantaranya seperti gambar 5. Sistem dapat dijalankan setelah dilakukan proses login baik login sebagai admin, prodi maupun mahasiswa. Masing-masing pengguna dapat menjalankan aplikasi melalui menu pilihan setiap pengguna.[8]

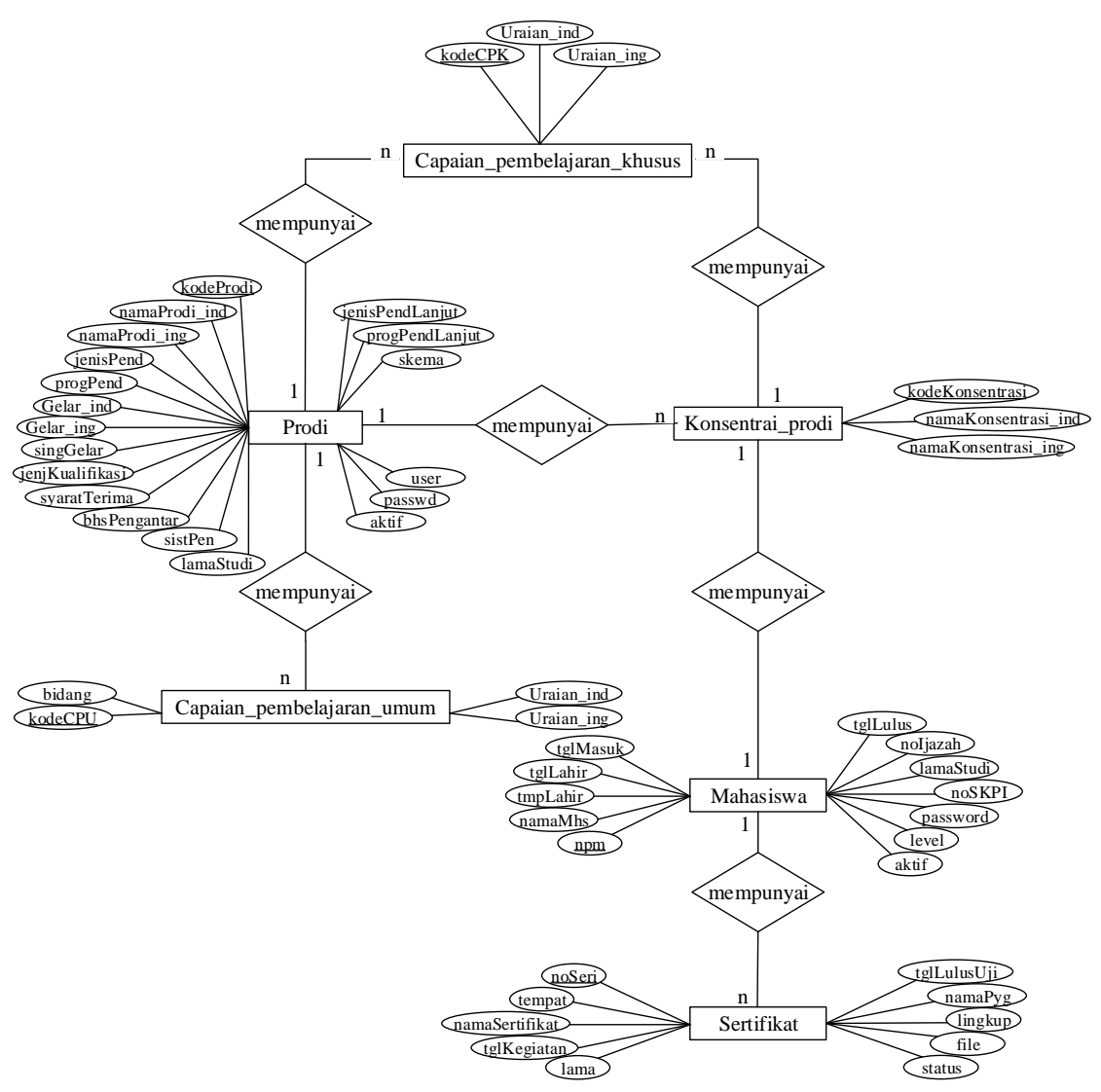

Gambar 4. ERD Sistem E-SKPI Fakultas Teknik Universitas Islam Riau 
IT Journal Research and Development

Vol.3, No.1, Agustus 2018

e-ISSN: 2528-4053

DOI : 10.25299/itjrd.2018.vol3(1).2091

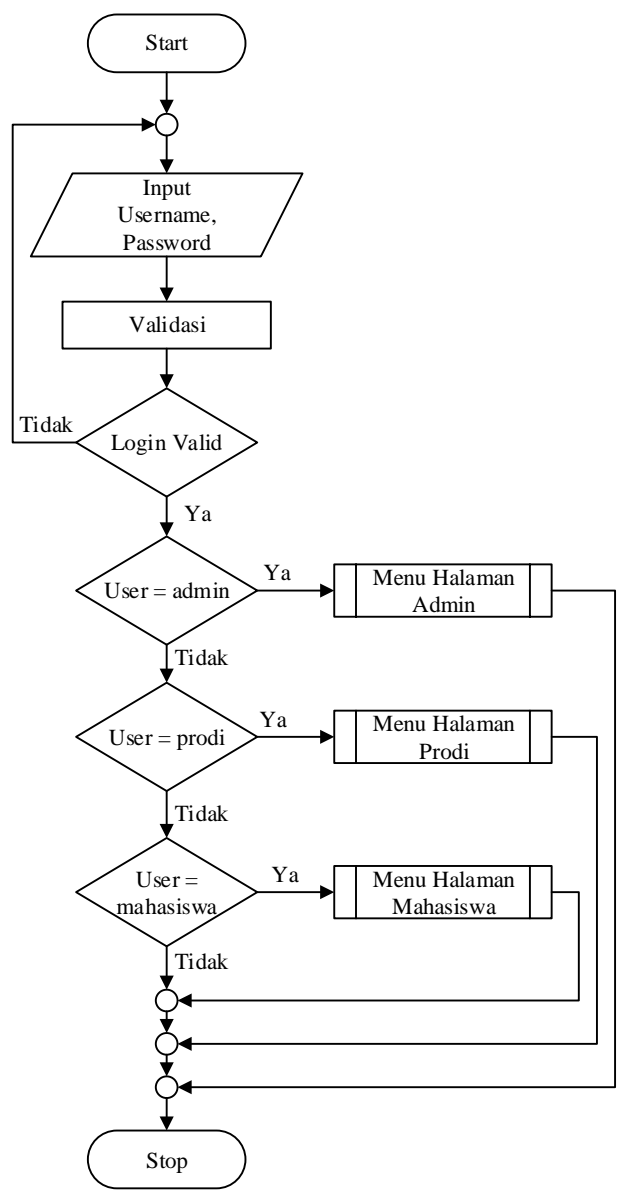

Gambar 5. Program Flowchart Login

\section{HASIL DAN PEMBAHASAN}

Aplikasi E-SKPI ini dapat dijalankan oleh 3 (tiga) user yaitu Admin yang ditunjuk oleh pimpinan di fakultas Teknik, semua Program Studi dan mahasiswa yang aktif di lingkungan fakultas Teknik Universitas Islam Riau.

1. User sebagai Admin, dapat menambahkan user baru baik prodi maupun mahasiswa dan mengelola semua yang dapat dijalankan sistem.

2. User sebagai Mahasiswa, dapat mengupload sertifikat seperti yang ditunjukkan pada gambar 6 . 
IT Journal Research and Development

Vol.3, No.1, Agustus 2018

e-ISSN: 2528-4053

DOI : 10.25299/itjrd.2018.vol3(1).2091

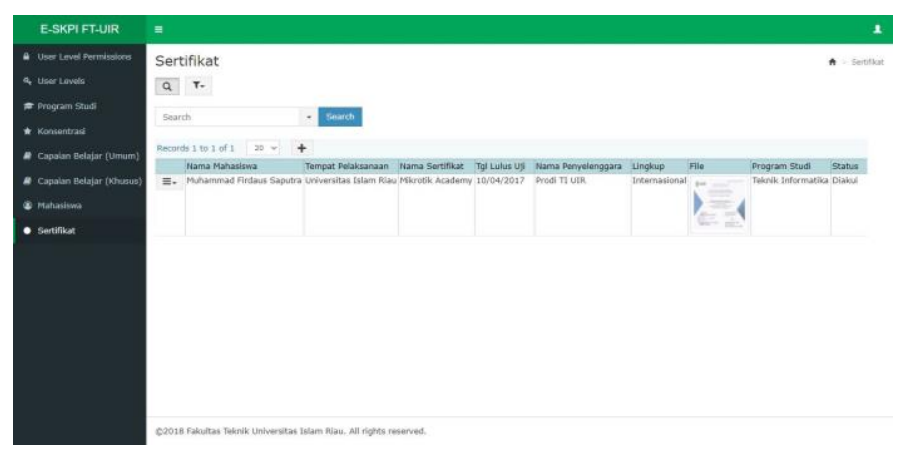

Gambar 6. Hasil Upload Sertifikat Mahasiswa

3. User sebagai Prodi, dapat menambahkan konsentrasi baru pada masing-masing prodi maupun melakukan verifikasi terhadap sertifikat yang diupload mahasiswa dan mencetak SKPI seperti yang digambarkan pada gambar 7 .

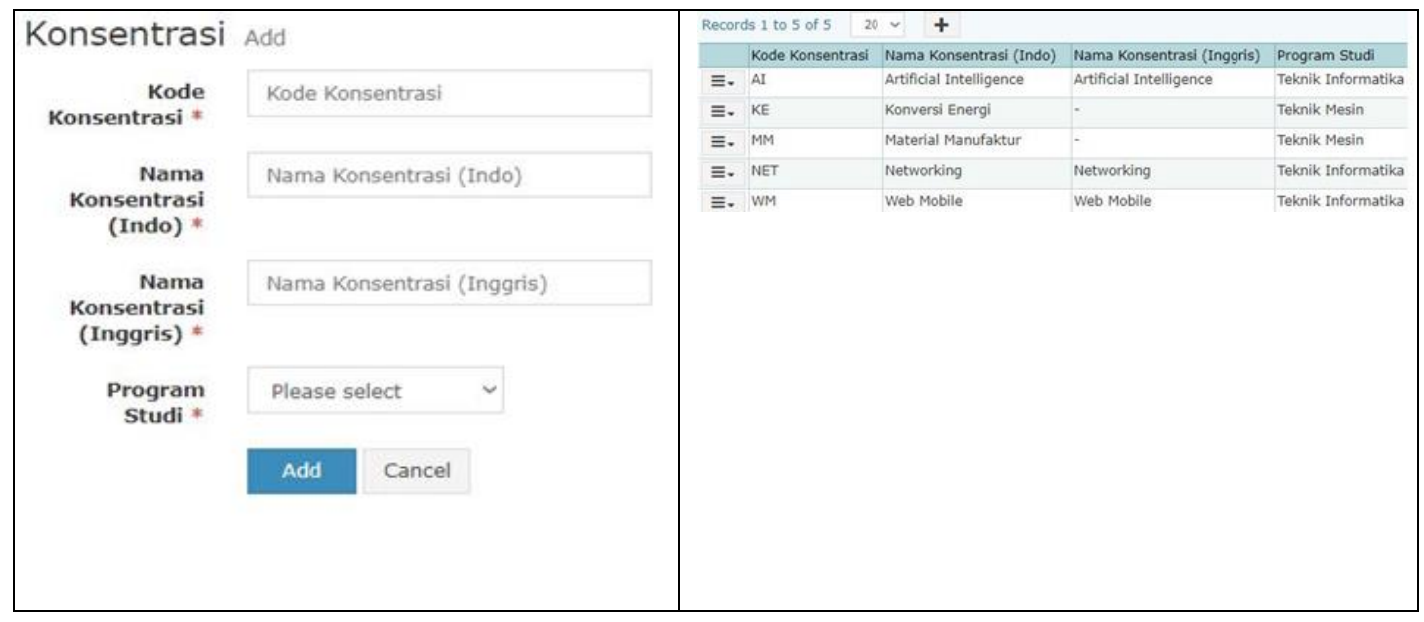

Gambar 7. Tambah Data Konsentrasi Prodi dan Hasilnya

8.

Di samping itu, prodi juga dapat mencetak SKPI secara langsung seperti gambar 


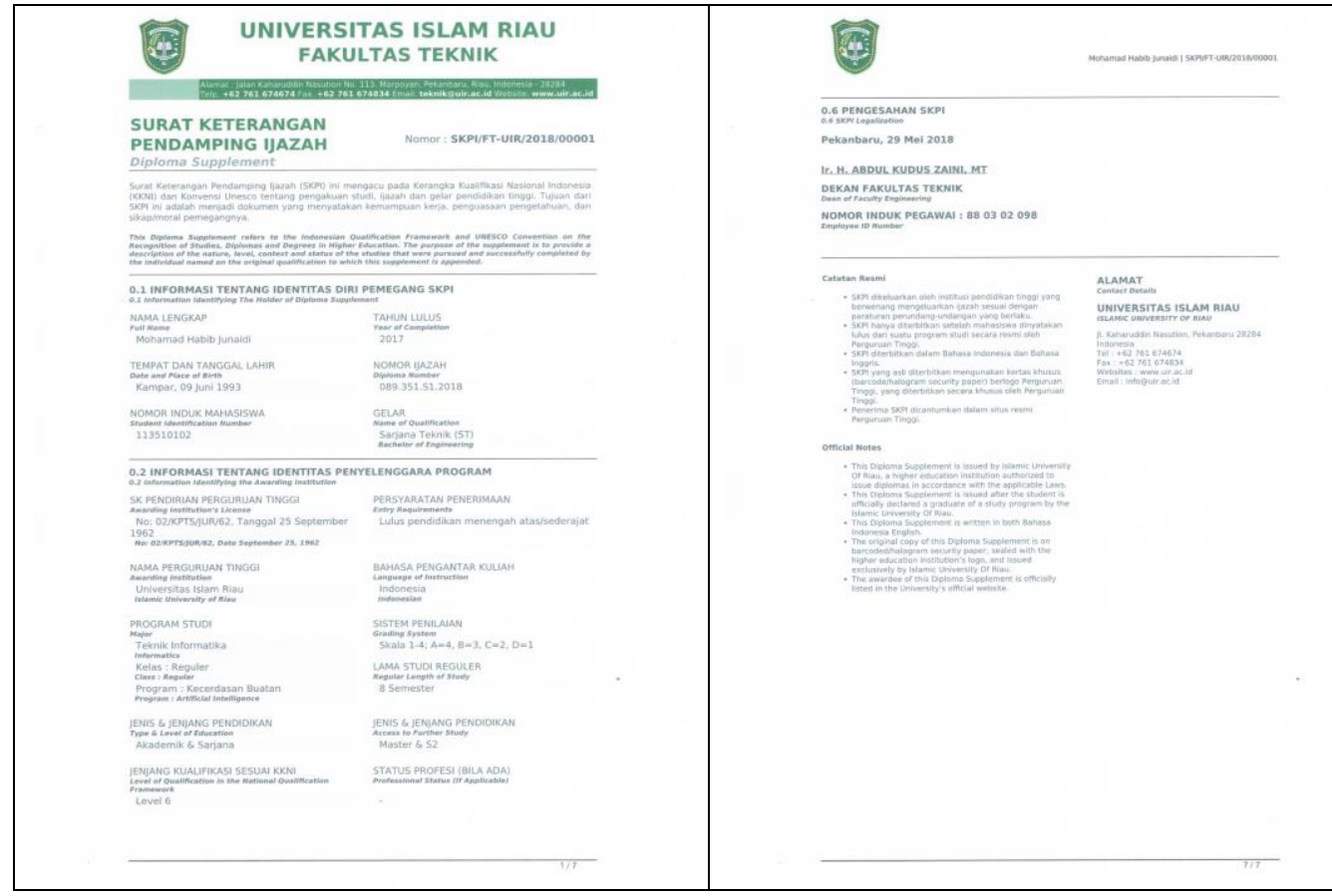

\section{Gambar 8. Surat Keterangan Pendamping Ijazah (SKPI) yang Dihasilkan}

Sistem yang telah dibangun dilakukan pengujian terlebih dahulu, pengujian dilakukan untuk mengetahui hasil yang diberikan sistem E-SKPI Fakultas Teknik Universitas Islam Riau. Dari sisi pengguna sistem menampilkan beberapa menu diantaranya adalah menu user level permissions, user levels, program studi, konsentrasi prodi, capaian pembelajaran umum, capaian pembelajaran khusus, mahasiswa, sertifikat dan logout.

Dalam proses pengujian sistem melewati beberapa tahapan diantaranya login sistem yang dilakukan oleh pengguna, Sebelum aplikasi yang di bangun dipublikasikan, ada beberapa tahapan yang harus dilakukan, hal ini dimaksudkan agar sewaktu aplikasi benar-benar sudah dipublikasikan tidak terjadi lagi kesalahan. Dalam pengujian sistem ini dilakukan dengan pengujian Black Box.

\section{Kesimpulan Hasil Pengujian Black Box}

Berdasarkan hasil pengujian dengan menggunakan black box, sistem yang sudah dilakukan maka diperoleh kesimpulan sebagai berikut :

1. Dari halaman menu yang disediakan semuanya berfungsi.

2. Penginputan data user levels permessions, user levels, program studi dan mahasiswa dilakukan oleh admin fakultas teknik.

3. Penginputan data konsentrasi prodi, capaian pembelajaran umum dan capaian pembelajaran khusus dilakukan oleh prodi fakultas teknik.

4. Penginputan data sertifikat dan upload file sertifikat dilakukan oleh mahasiswa. 


\section{KESIMPULAN}

Penelitian ini telah berhasil dilakukan dan memberikan beberapa kesimpulan yaitu:

1. Aplikasi ini dapat dijalankan oleh 3 (tiga) user yaitu Admin yang ditetapkan fakultas Teknik, semua Program Studi pada fakultas Teknik dan mahasiswa yang aktif di lingkungan fakultas Teknik Universitas Islam Riau.

2. Admin dapat mengelola data user secara keseluruhan, seperti melakukan penambahan data user baru, edit dan hapus data user yang ada.

3. Prodi dapat melakukan penambahan data konsentrasi baru, edit dan hapus data konsentrasi prodi yang ada dan melakukan verifikasi terhadap data sertifikat mahasiswa yang telah diupload mahasiswa.

4. Admin dan Prodi dapat mencetak Surat Keterangan Pendamping Ijazah secara online.

5. Mahasiswa dapat mengupload data sertifikat secara online.

\section{SARAN}

Hasil penelitian ini dapat dijadikan sebagai bahan acuan untuk pengembangan penelitian berikutnya berupa pembuatan SKPI di tingkat universitas maupun seluruh perguruan tinggi dibawah naungan Kopertis Wilayah X.

\section{DAFTAR PUSTAKA}

[1] Sari, K. D. A. dan Wahyu Agus Winarno. (2012). Implementasi E-Government System Dalam Upaya Peningkatan Clean And Good Governance di Indonesia. JEAM Vol XI No. 1, ISSN: 1412-5366

[2] Hartono, Dwiarso Utomo dan Edy Mulyanto. (2010). Electronic Government Pemberdayaan Pemerintahan Dan Potensi Desa Berbasis Web. Jurnal Teknologi Informasi. Volume 6 Nomor 1, ISSN 1414-9999.

[3] Betha, Sidik. (2004). Pemrograman Web dengan PHP. Informatika. Bandung.

[4] Dhanta. (2009), Sistem Informasi Manajemen. PT. Pustaka Binaman Pressindo. Jakarta.

[5] Hardjono, Dhewiberta. (2006). Seri Panduan Lengkap Menguasai Pemrograman Web dengan PHP 5. Andi Offset. Yogyakarta.

[6] Kadir, A. (2002). Pemograman Web Mencakup : HTML,CSS, Javascript \& PHP. Jilid I. Penerbit Andi. Yogyakarta.

[7] Kadir, A. (2003). Dasar Pemograman Web Dinamis Menggunakan PHP. Penerbit Andi. Yogyakarta.

[8] Suryani D., Labellapansa A., Marsela E. (2018) Accuracy of Algorithm C4.5 to Study Data Mining Against Selection of Contraception. In: Saian R., Abbas M. (eds) Proceedings of the Second International Conference on the Future of ASEAN (ICoFA) 2017 - Volume 2. Springer, Singapore 